MATEC Web of Conferences 47, 03009 (2016)

DOI: $10.1051 /$ matecconf/20164703009

(C) Owned by the authors, published by EDP Sciences, 2016

\title{
Pavement Response to Variable Tyre Pressure of Heavy Vehicles
}

\author{
Ahmad Kamil Arshad ${ }^{1, a}$, Hairol Anuar Haron ${ }^{2}$, Zanariah Abd Rahman ${ }^{3}$ and A.G. Abdul Halim ${ }^{4}$ \\ ${ }^{1}$ Institute for Infrastructure Engineering and Sustainable Management, Universiti Teknologi Mara, 40450 Shah Alam, \\ Selangor, Malaysia \\ ${ }^{2}$ Faculty of Civil Engineering, Universiti Teknologi Mara, 81750 Masai, Johor, Malaysia \\ ${ }^{3}$ Faculty of Civil Engineering, Universiti Teknologi Mara, 40450 Shah Alam, Selangor, Malaysia \\ ${ }^{4}$ Faculty of Civil and Environmental Engineering, Universiti Tun Hussein Onn Malaysia, 86400 Parit Raja, Johor, \\ Malaysia
}

\begin{abstract}
In recent years, the effect of overinflated tyre pressure and increased heavy vehicles' axle load on flexible pavements has become a subject of great concern because of the higher stress levels induced and damage caused to road pavements. This paper aims to evaluate the effect of variable tyre inflation pressures (using actual tyre contact/footprint area) to determine the responses of flexible pavement. A full scale experiment was conducted on a heavy vehicle with 1:1:2 axle configuration, 10 R 20 tyre size and attached trailer with constant axle load. Measurements were made for actual tyre-pavement contact area. KENPAVE linear elastic program was then used to analyse the effects of the measured actual tyre-pavement contact area and the results was compared using conventional circular tyre contact area. A comparative analysis was then made between the actual contact area and the conventional circular tyre contact area. It was found that high tyre inflation pressure produce smaller contact area, giving more detrimental effect on the flexible pavement. It was also found that the temperature of tyres when the heavy vehicles are operational give less significant impact on tyre inflation pressure for the Malaysian climate.
\end{abstract}

\section{Introduction}

The Government of Malaysia currently spends a substantial amount of money to maintain and rehabilitate road pavements. Heavy vehicles' overloading is one of the major factors contributing to pavement damage, in addition to other factors such as poor road construction and effect of the environment [1] [2]. As a consequence to the heavy vehicles' overloading, most of the truck operators increased the tyre inflation pressure to reduce tyre wear and tear thus increasing the life of the heavy vehicles' tyres. Therefore, a study on the detrimental effect of increasing tyre inflation pressure on the flexible pavement is important for designing flexible pavement structures.

A vehicle's loading is transferred to the pavement structure through the tyres. The interface between the tyre and pavement is generally assumed to be circular contact area and the relationship between tyre inflation pressure and contact area is given by following formula [3]:

\footnotetext{
${ }^{\text {a }}$ Corresponding author : drahmadkamil@salam.uitm.edu.my
} 


$$
p=\frac{P}{a^{2} \pi}
$$

where: $p=$ tyre pressure in $k P a, P=$ total load on the tyre in $k N$, and $a=$ radius of contact in $m$.

Studies carried out on non-uniform tyre contact area using finite element and linear elastic programmes found significant effect on flexible pavement layers due to the increased in tensile and compressive strains [4-6]. According to Sebaaly, the magnitude and frequency of loading from the tyre to the pavement surface interface can influence the tyre contact area and tyre contact pressure [7]. In addition, Sebaaly and Tabatabaee found that tyre contact area depends on the tyre inflation pressure and tyre structure that influence the critical tensile strain at the bottom of the asphalt layer, surface deflection and compressive strength at the interface between the base and the asphaltic concrete [8].

This paper aims to evaluate the effect of variable tyre inflation pressures (using actual tyre footprint area) to determine the responses of flexible pavement. Analysis will be carried out to evaluate the impact of tyre inflation pressure on the allowable axle load repetitions for fatigue and permanent deformation based on Asphalt Institute's equations [9]. The analysis will determine the impact of overinflated tyre pressure on flexible pavements responses which has become a subject of great concern because of the higher stress level induced and causing increased damage to road pavements.

\section{Methodology}

A full scale experiment work was carried out to determine the effect of variable tyre inflation pressure on tyre contact area. The truck used in the experiment was a four-axle (single axle steer with single axle drive and dual tyre rear tandem) 32-tonne gross vehicle weight (GVW) and fitted with $10 \mathrm{R} 20$ tyres. Only the rear tandem axle was tested and the recommended tyre inflation pressure was chosen based on the tyre pressure data printed on the side wall of the tyre. Tyre inflation and deflation were carried out manually using a tyre inflation system with portable power source and an air compressor with a maximum working pressure of up to $1034 \mathrm{kPa}$ (150 psi). The experiment was carried out on an existing flexible pavement at parking area in Universiti Teknologi MARA (UiTM), Shah Alam, Malaysia. Properties of existing pavement condition such as strength and pavement layer thickness was determined using falling weight deflectometer (FWD), coring test and dynamic cone penetrometer (DCP). The experimental works were conducted for two sessions, in the morning $(0800 \mathrm{hr}-1000 \mathrm{hr})$ and in the afternoon $(1230 \mathrm{hr}-1430 \mathrm{hr})$. The different sessions were conducted to measure the effects of temperature difference, particularly for the afternoon session, whereby the surface layer is at a higher temperature and therefore at a lower stiffness level. The lower stiffness value of the surface layer will reduce the load carrying capacity of the pavement. The temperature of the pavement surface and tyre were recorded during the experiment using non-contact infrared thermometer.

Tyre inflation pressure was set at the recommended tyre inflation pressure (676 $\mathrm{kPa}$ or $98 \mathrm{psi}$ ) printed at tyre side wall and then increased up to $50 \%$ above the recommended tyre pressure at increments of $10 \%$. The tyre was then decreased up to $50 \%$ of the recommended tyre inflation pressure at increments of $10 \%,(338 \mathrm{kPa}$ or $49 \mathrm{psi}-676 \mathrm{kPa}$ or $98 \mathrm{psi}-1014 \mathrm{kPa}$ or $147 \mathrm{psi})$. Each inflation pressure was evaluated three times at separate sides of the tyre (right hand side outer tyre, right hand side inner tyre, left hand side outer tyre and left hand side inner tyre) for a total of 12 tyre footprint measurements for each inflation pressure.

Tyre footprint was obtained by free fall (static) measurement conducted for four days in the morning (0800hr-1000hr) and afternoon (1230hr-1430hr) using glossy black paint, stamped on an A3size white paper underlain on a plastic cardboard of about $2 \mathrm{~mm}$ thick to avoid damaging the 80 gram A3 white paper due to the heavy vehicle loading. The tyre footprint was then scanned using a computer scanner.

Tyre footprint was calculated using computer software known as ImageJ v1.46 [9]. This software was designed to generate complicated non-uniform images. A scale was set in millimetres and 
calibrated with ordinary ruler measurement when scanning the tyre footprint images. After the scale was set, the image was then generated to calculate the non-uniform (actual) area for each region of the tyre contact area.

\section{Results and Discussion}

As the tyre pressure increases, the tyre-pavement contact area decreases for both sessions. The quadratic form models (for actual tyre contact area obtained versus tyre inflation pressure) during the morning session for both the right hand side (RHS) tyre and left hand side (LHS) tyre gave $\mathrm{r}^{2}$ value of above 0.9 for all measurements of the tyre contact area when the tyre was deflated from $1014 \mathrm{kPa}$ (147 psi) to $339 \mathrm{kPa}$ (49 psi) (Figure 1). However, it was observed that there is a lower value of tyre contact area for the RHS outer tyre for both sessions. There is a large gap in value between those groups and the RHS outer tyre, possibly due to the problem of axle alignment or tyre tread condition. It can be seen that there is a big difference between conventional method and actual tyre contact area when the tyre inflation pressure starts to increase, however, for tyre pressure between $476 \mathrm{kPa}$ (69 psi) to $607 \mathrm{kPa}(88 \mathrm{psi})$, the difference is less than $10 \%$.

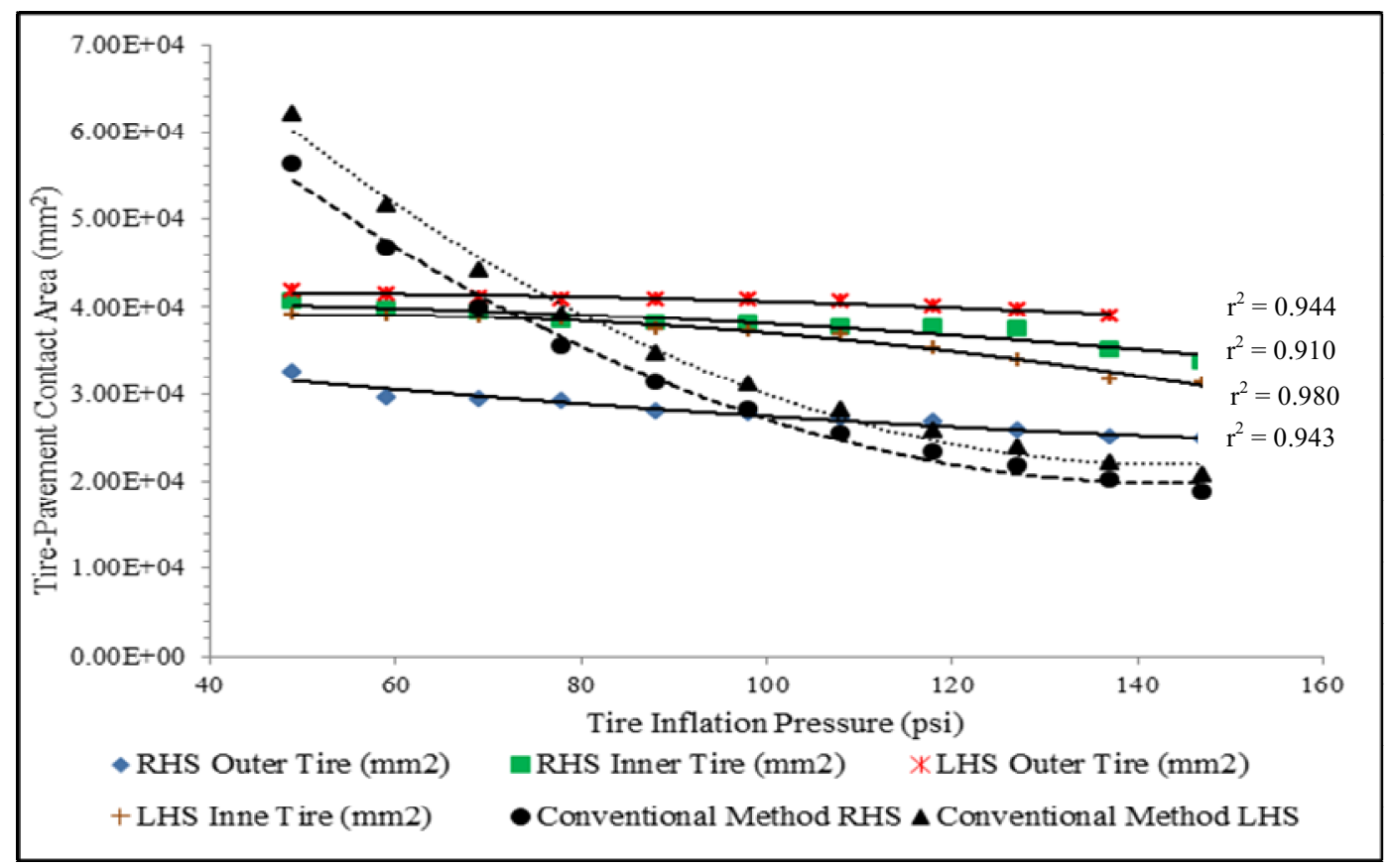

Figure 1. Correlation between tyre inflation pressure and tyre contact area for morning session.

For the afternoon session, the behaviour of tyre contact pressure act almost similar to the morning session. Figure 2 shows the quadratic form models for the RHS, LHS tyre axle and the conventional calculated circular area method. For tyre inflation pressure between $476 \mathrm{kPa}$ (69 psi) to $538 \mathrm{kPa}$ (78 psi), there is less than $10 \%$ difference between conventional and actual non-uniform contact area. On RHS outer tyre, almost all tyre inflation pressure are similar except for $814 \mathrm{kPa}$ (118 psi) and 876 $\mathrm{kPa}(127 \mathrm{psi}$ ) (over 10\%) due to the effects of mechanical alignment problem or uneven tyre tread surface. However, it was observed that there is lower value of tyre contact area for the RHS outer tyre for both sessions. 


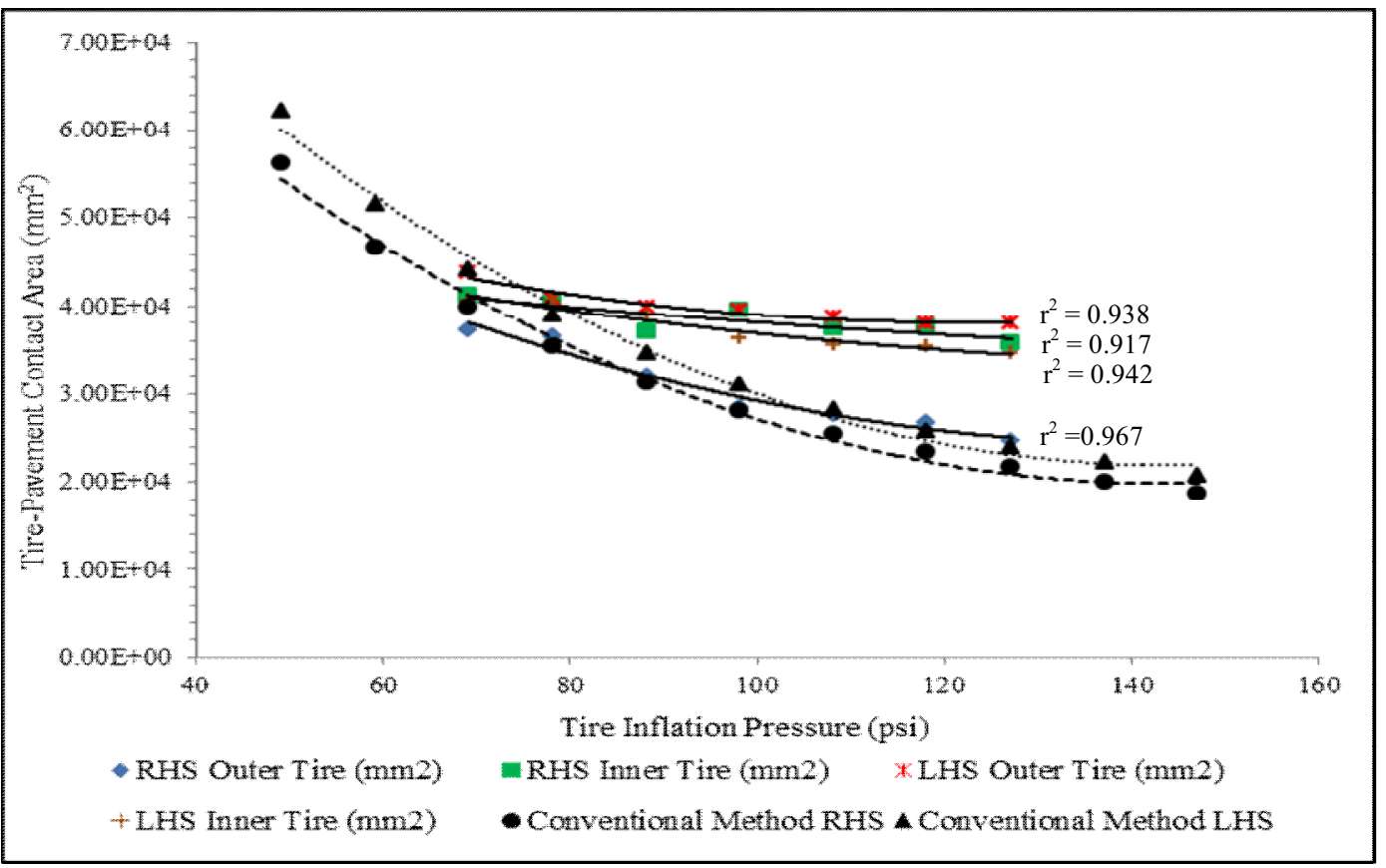

Figure 2. Correlation between tyre inflation pressure and tyre contact area for afternoon session.

\section{Analysis of Pavement Response}

Only the tyre inflation pressure range from $476 \mathrm{kPa}(69 \mathrm{psi})$ to $876 \mathrm{kPa}$ (127 psi) with constant axle load of $80 \mathrm{kN}$ were analysed in order to evaluate the critical tensile strain at the bottom of asphalt layer, and critical vertical compressive strain at the top of subgrade in the middle of the tyre contact area. For the conventional circular area method, when the tyre inflation pressure increased (decrease of radius in tyre contact area), the tensile and compressive strains increased in value. This caused a decrease in the allowable axle load repetitions for both fatigue and permanent deformation, as shown in Table 1. However, the allowable load repetition for fatigue is lower than the allowable load repetition for permanent deformation in all cases.

Table 1. Pavement response for conventional circular area method.

\begin{tabular}{|c|c|c|c|c|c|}
\hline $\begin{array}{l}\text { Tyre } \\
\text { Inflation } \\
\text { Pressure } \\
\text { (kPa) }\end{array}$ & $\begin{array}{l}\text { Radius of Circular } \\
\text { Contact Area by } \\
\text { Conventional } \\
\text { Method (cm) }\end{array}$ & $\begin{array}{c}\text { Tensile } \\
\text { Strain, } \epsilon_{t} \\
\left(1 \times 10^{-4}\right)\end{array}$ & $\begin{array}{c}\text { Compressive } \\
\text { Strain, } \epsilon_{c} \\
\left(1 \times 10^{-4}\right)\end{array}$ & $\begin{array}{l}\text { Allowable Load } \\
\text { Repetition for } \\
\text { Fatigue } \\
\text { Prediction } \\
\begin{array}{c}(1 \times 10) \\
\end{array}\end{array}$ & $\begin{array}{c}\text { Allowable Load } \\
\text { Repetition for } \\
\text { Permanent } \\
\text { Deformation } \\
\text { Prediction } \\
(1 \times 10) \\
\end{array}$ \\
\hline 475.74 & 11.27 & 4.91 & 3.59 & 3.60 & 361 \\
\hline 537.79 & 10.60 & 5.29 & 3.61 & 2.81 & 353 \\
\hline 606.74 & 9.98 & 5.66 & 3.62 & 2.25 & 348 \\
\hline 675.69 & 9.46 & 6.00 & 4.95 & 1.86 & 85.8 \\
\hline 744.63 & 9.01 & 6.27 & 4.96 & 1.61 & 85.0 \\
\hline 813.58 & 8.62 & 6.50 & 5.37 & 1.42 & 59.6 \\
\hline 875.63 & 8.31 & 6.69 & 5.89 & 1.30 & 39.4 \\
\hline
\end{tabular}


Table 2 shows the pavement response for the actual measured contact area in the morning session. As the tyre inflation pressure increased, the radius of the actual tyre contact area decreased. The actual tensile strain for the morning session increased when the actual contact area decreased and the difference was as high as $27 \%$ compared to the tensile strains calculated using the conventional circular area. For the compressive strain, the difference was only $12 \%$ but still above the conventional circular area method. As with the conventional circular area method, the allowable load repetition for fatigue is lower than the allowable load repetition for permanent deformation in all cases.

Pavement response for the afternoon session is shown in Table 3. The difference between conventional method and actual measured contact area is $25 \%$ for tensile strain and $12 \%$ for the compressive strain analysis. Similarly, as in the morning session, the allowable load repetition for fatigue is lower than the allowable load repetition for permanent deformation in all cases.

Table 2: Pavement response for morning session with actual tyre contact area.

\begin{tabular}{|c|c|c|c|c|c|}
\hline $\begin{array}{c}\text { Tyre } \\
\text { Inflation } \\
\text { Pressure } \\
(\mathbf{k P a})\end{array}$ & $\begin{array}{l}\text { Radius of Actual } \\
\text { Contact Area } \\
\text { Morning (cm) }\end{array}$ & 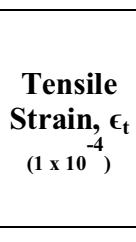 & $\begin{array}{c}\text { Compressive } \\
\text { Strain, } \epsilon_{\mathrm{c}} \\
\left(\begin{array}{l}1 \times 10^{-4} \\
\text { (n) }\end{array}\right.\end{array}$ & $\begin{array}{c}\text { Allowable } \\
\text { Load } \\
\text { Repetition for } \\
\text { Fatigue } \\
\text { Prediction } \\
(1 \times 10) \\
\end{array}$ & $\begin{array}{c}\text { Allowable Load } \\
\text { Repetition for } \\
\text { Permanent } \\
\text { Deformation } \\
\text { Prediction } \\
(1 \times 10) \\
\end{array}$ \\
\hline 475.74 & 10.85 & 4.78 & 3.16 & 3.93 & 637 \\
\hline 537.79 & 10.80 & 5.38 & 3.54 & 2.66 & 383 \\
\hline 606.74 & 10.69 & 6.02 & 3.92 & 1.84 & 244 \\
\hline 675.69 & 10.67 & 6.70 & 4.35 & 1.29 & 153 \\
\hline 744.63 & 10.62 & 7.35 & 4.75 & 0.95 & 103 \\
\hline 813.58 & 10.51 & 7.96 & 5.09 & 0.73 & 75.8 \\
\hline 875.63 & 10.40 & 8.49 & 5.37 & 0.59 & 59.7 \\
\hline
\end{tabular}

Table 3: Pavement response for afternoon session with actual tyre contact area.

\begin{tabular}{|c|c|c|c|c|c|}
\hline $\begin{array}{c}\text { Tyre } \\
\text { Inflation } \\
\text { Pressure } \\
(\mathbf{k P a})\end{array}$ & $\begin{array}{c}\text { Radius of Actual } \\
\text { Contact Area } \\
\text { Afternoon (cm) }\end{array}$ & $\begin{array}{c}\text { Tensile } \\
\text { Strain, } \boldsymbol{\epsilon}_{\mathbf{t}} \\
(\mathbf{1 \times \mathbf { 1 0 }})\end{array}$ & $\begin{array}{c}\text { Allowable } \\
\text { Compressive } \\
\text { Strain, } \boldsymbol{\epsilon}_{\mathbf{c}} \\
(\mathbf{1 \times 1 0})\end{array}$ & $\begin{array}{c}\text { Allowable Load } \\
\text { Load } \\
\text { Repetition for } \\
\text { Fatigue } \\
\text { Prediction } \\
(\mathbf{1} \times \mathbf{4})\end{array}$ & $\begin{array}{c}\text { Repetition for } \\
\text { Permanent } \\
\text { Deformation } \\
\text { Prediction } \\
(\mathbf{1} \times \mathbf{4})\end{array}$ \\
\hline 475.74 & 11.39 & 4.95 & 3.47 & 3.49 & 421 \\
537.79 & 11.22 & 5.54 & 3.81 & 2.42 & 276 \\
606.74 & 10.85 & 6.09 & 4.03 & 1.76 & 215 \\
675.69 & 10.68 & 6.70 & 4.36 & 1.29 & 152 \\
744.63 & 10.52 & 7.29 & 4.67 & 0.97 & 112 \\
813.58 & 10.45 & 7.92 & 5.03 & 0.74 & 79.6 \\
875.63 & 10.26 & 8.39 & 5.23 & 0.62 & 67.1 \\
\hline
\end{tabular}

\section{Conclusion}

The actual measured contact area for the morning and afternoon session was measured and compared with the conventional calculated circular area. The results showed that there is a $10 \%$ difference between actual tyre contact area measured for tyre inflation pressure range of between $476 \mathrm{kPa}(69$ 


\section{MATEC Web of Conferences}

psi) to $607 \mathrm{kPa}$ (88 psi) compared to the conventional circular area method. Above the $607 \mathrm{kPa}(88$ psi), the conventional circular area method gives much lower value for tyre contact area than the actual measured area, resulting in lower tensile strain value.

Using KENPAVE computer program, the pavement response showed a difference of $25 \%$ to $27 \%$ for tensile strains between actual measured contact area and conventional circular area method for both morning and afternoon sessions respectively. The compressive strain showed only $12 \%$ difference between the measured and conventional circular area for both sessions. Similarly, as with the conventional circular area method and actual measured area, the allowable load repetition for fatigue is lower than the allowable load repetition for permanent deformation in all cases.

It is recommended that the study is expanded for other types of heavy vehicles on the full scale experimental approach to investigate the effects of tyre inflation pressure and temperature because of the difficulty to obtain the data when the heavy vehicles are in operation.

\section{References}

[1] Roadscanners Oy, Effect of axle and tyre configurations on pavement durability - a prestudy, The ROADEX Network, Finland, (2014).

[2] A.E. Behiry and A.Y. Beltagy, Mechanistic-empirical study of sensitivity of truck tire pressure to asphalt pavement thickness in Egypt, Int. J. of Eng. Res. and Apps., 3(5), 1760-1771, (2013).

[3] E.J. Yoder and M.W. Witczak, Principles of Pavement Design, John Wiley and Sons, New York, (1975).

[4] D. Moazami, R. Muniandy, H. Hamid and Z.M. Yusof, Effect of tire footprint area in pavement response studies, Int. J. of Physical Sciences, 6(21), 5040-5047, (2011).

[5] M.H. Nahi, A. Ismail and A.K. Arifin, Analysis of asphalt pavement under non-uniform tirepavement contact stress using finite element method, J. of App.Sci., 11(14), 2562-2569, (2011).

[6] D.W. Park, A.E. Martin, J.H. Jeong,and S.T. Lee, Effect of tyre inflation pressure and load on predicted pavement strains, The Baltic J. of Road and Bridge Eng., 3(4), 181-186, (2008).

[7] P.E. Sebaaly, Pavement damage as related to tyres, pressure, axle loads, and configurations, ASTM STP 1164, 54-68, (1992).

[8] P.E. Sebaaly and N. Tabatabaee, Effect of tyre parameter on pavement damage and loadequivalency factors, ASCE J. of Trans. Eng., 118(6), 805-819, (1992).

[9] Asphalt Institute, Thickness Design Manual (MS-1), Lexington, (1981).

[10] Information on http://rsb.info.nih.gov/ij/index.html 